\title{
Democracia na tensão entre o conser- vadorismo e a utopia: por uma reorientação constituinte de sentido a partir dos movimen- tos sociais e das manifestações populares
}

Democracy in tension between conservatism and utopia: for a reorientation of meaningful constituent from social movements and popular manifestations

Resumo: O presente artigo tem como objetivo propor a reorientação da política e um novo paradigma de democracia, com participação mais simétrica, mais inclusiva dos cidadãos e dos excluídos, com maior potencial transformador, fora do ceticismo e do conservadorismo do Direito. O principal marco teórico é a filosofia política de Enrique Dussel. Como pano de fundo, tem-se o estado de exceção permanente em que vivem os excluídos, os movimentos sociais e os protestos contra a classe política que ocorrem desde 2013 no Brasil. A pesquisa se desenvolve com base na

1 Doutor em Direito pela Universidade de Brasília (UnB). Professor das pós-graduações do Insituto Brasiliense de Direito Público e da Escola da Magistratura do Distrito Federal. Juiz de Direito do TJDFT. 
opção de uma linha crítico-metodológica, mas não se exime de ser propositiva, mediante o oferecimento de alternativas ao paradigma atual de democracia e ao modo de fazer política no Brasil. Ao final, conclui-se que as alternativas concretas devem ser buscadas com base num paradigma de democracia discursiva, comunitária e emancipadora, para além do sistema tradicional de tripartição de poderes, que gere efetivo empoderamento do povo e da comunidade, mas também em propostas concretas, a partir das experiências latino-americanas, que devem ser discutidas e internalizadas à luz da realidade brasileira, e que tem a pretensão de devolver ao povo a centralidade do poder político.

Palavras-chave: Democracia emancipadora. Manifestações populares. Poder simbólico. Estado de exceção permanente. Experiências latino-americanas.

Abstract: This article aims to propose a reorientation of the politics and a new paradigm of democracy, with more symmetrical participation, more inclusive of citizens and excluded, more transformative potential, out of the skepticism of Political Science and Law conservatism. The main theoretical framework is the political philosophy of Enrique Dussel. As a backdrop, there are the permanent state of exception in which excluded social groups live and the protests against the political class that have taken place since 2013 in Brazil. The research is developed based on the option of a critical-methodological approach, but it is not exempt from being purposeful, by offering alternatives to the current paradigm of democracy and the way of doing politics in Brazil. Finally, it is concluded that the concrete alternatives should be sought on the basis of discursive, communitary and emancipatory democracy paradigm, beyond 
the traditional system of tripartite powers, which leads to effective empowerment of the people and the community, but also in concrete proposals, from the Latin American experience, which should be discussed and internalized in the light of Brazilian reality, and that has the intention of returning to the people the centrality of political power.

Keywords: Emancipatory democracy. Popular manifestations. Symbolic power. Permanent state of exception. Latin American experiences.

\section{Introdução}

Em 20 de junho de 2013, mais de um milhão de brasileiros foram às ruas das diversas cidades brasileiras para prostestar. Pesquisas de campo monstraram que a maioria dos manifestantes dizia não se sentir representada por partido $(89 \%)$, nem pela classe política brasileira (83\%). Além disso, a maior reivindicação dos manifestantes era por mudanças no ambiente político. ${ }^{2}$ Em outra pesquisa de opinião, os entrevistados disseram que as manifestações tinham como um dos principais motivos o combate à corrupção e o descontentamento contra os políticos em geral. ${ }^{3}$ Diversas outras manifestações foram feitas contra a classe política, sendo que, em 15 de março de 2015, mais de 2,4 milhões de pessoas foram às ruas, em todos os Estados e no Distrito Federal. ${ }^{4}$ Em 12 de abril 2015, mais de 700 mil pessoas saíram de suas casas para se manifestar 5 . Desde então, até o final do ano de

\footnotetext{
2 IBOPE, 2018-a.

3 IBOPE, 2018-b, p. 55.

4 G1, 2018-a

5 G1, 2018-b.
} 
2017, já havia ocorrido mais de 23 grandes manifestações populares contra a classe política no país. ${ }^{6}$

A partir disso, é preciso buscar uma reorientação da política e do atual modelo de democracia, com base numa filosofia política que seja capaz de internalizar a voz das manifestações populares, as reivindicações dos movimentos sociais e o grito dos excluídos.

Nesse contexto, o presente artigo tem o objetivo de buscar uma reorientação da política e um novo paradigma de democracia, com participação mais simétrica, mais inclusiva dos cidadãos e dos excluídos, com maior potencial transformador, fora do conservadorismo do Direito, tendo como principal marco teórico a filosofia política de Enrique Dussel, e levando em consideração, sobretudo, o estado de exceção permanente em que vivem os excluídos, os movimentos sociais e os protestos recentes que marcam as manifestações desde 2013 no Brasil.

Para atingir esses escopos, a pesquisa se desenvolve com base na opção de uma linha crítico-metodológica. Entretanto, a par da perspectiva crítica e reflexiva, a investigação da presente pesquisa não se eximirá de ser propositiva, mediante o oferecimento de alternativas democráticas ao paradigma atual de democracia e ao modo de fazer política no Brasil.

Assim, o presente artigo foi dividido em três partes. $\mathrm{Na}$ primeira, busca-se desconstruir algumas aporias e dogmas, sobretudo do Direito, a partir do poder simbólico em Pierre Bourdieu, a fim de mostrar os mecanismos de dominação pelo Direito e aquilo que ele encobre. Além disso, busca investigar se, na perspectiva dos grupos hegemônicos há democracia, existe estado de exceção permanente em que vivem os excluídos. Assim, pretende-se colocar em xeque os

6 G1, 2018-c. 
atuais modelos de fazer política e a concepção eurocêntrica de democracia, para propor a sua ressignificação a partir da sua radicalidade transformadora, e com a perspectiva dos movimentos sociais e das manifestações populares. Após essa análise teórica, que é crítica da realidade, passa-se a buscar elementos para a descolonização da filosofia política e a reconstrução das instituições à luz das peculiaridades de cada comunidade política, com o objetivo de despertar inquietações para buscar novos horizontes para a democracia, com base na filosofia política de Dussel. Nesse sentido, propõe-se a reconstrução de um novo paradigma de democracia, mais procedimentalista e comunitária, que gere o empoderamento do povo e a valorização dos saberes locais de cada comunidade. Na terceira parte, tem-se a pretensão de traçar as bases para reconstruir um novo paradigma de democracia discursiva e comunitária a partir da abertura de um espaço de descontinuidade nos modelos político-institucionais atuais, ou seja, a partir do retorno à vida nua. Após a proposição de uma nova aporia, apresentam-se alternativas contrafactuais de tomada do poder pelo povo, dentro e fora das instituições estatais, constituintes de postulados pela participação popular e comunitária efetiva. Além disso, são propostas alternativas concretas a partir de experiências latino-americanas, que devem ser discutidas à luz da realidade brasileira, mas que não têm a pretensão de ser definitivas. Ao contrário, devem ser inseridas num contexto de experimentalismo institucional. Enfim, são aporias e novas propostas para uma democracia discursiva e comunitária, que, a par de suas contingências, pretendem realocar o povo na centralidade do poder político, dentro e fora do Estado. 


\section{Desconstruindo ilusões: o conservadorismo do Direito, o Estado de exceção permanente, os excluídos e a democracia em sua radicali- dade modificadora}

No discurso do constitucionalismo brasileiro contemporâneo em geral, parte-se da perspectiva da normalidade das instituições democráticas, que seriam capazes de superar, inclusive, a crise política que se instaurou no país sobretudo a partir de 2013. Tem-se como pressuposto o fato de que se vive numa democracia, que os cidadãos elegem os governantes e, desse modo, participam da vida política do Estado por meio do voto. Esse é o discurso político e jurídico justificador de uma realidade que serve a alguns, mas que encobre grande parte da população, os excluídos. Enquanto esse discurso é reproduzido, ele mascara a realidade, pois não considera os excluídos de participação, os excluídos de acesso a bens e a direitos, os excluídos da dignidade. Aqui se pretende incluir não somente os sem-terra, os sem-teto e outros grupos organizados, mas também aqueles grupos marginalizados que não possuem um corpo, uma organização, que moram na periferia, que não têm acesso a serviços básicos, que estão encobertos, que são vistos como uma alteridade quase completa pelo olhar da classe política e das elites sociais; aquelas pessoas que são excluídas das políticas públicas, do olhar da mídia, da atenção dos governos. ${ }^{7}$

7 Aqui estão aqueles que não são considerados em sua individualidade, mas que são vistos pelo Estado apenas como um número, como estatística. A perspectiva crítica que se pretende desenvolver tem como pano de fundo a realidade social das periferias brasileiras e, mais especificamente, as diferenças da preocupação estatal entre os diversos grupos sociais. Por exemplo, quando há um roubo ou um homicídio em um bairro nobre, isso gera repercussão; quando o mesmo acontece com uma vítima na periferia, comumente há pouca atenção da polícia e da classe política, ela é vista apenas 
Assim, é possível observar que o direito, enquanto sistema simbólico de dominação, e pela perspectiva cética em relação ao jogo de interesses que permeia as relações nas instituições democráticas, tem servido à reprodução do modelo político atual, como se mostrará a seguir.

\subsection{A dominação pelo direito, a fetichização do poder e a exclusão social}

O direito, como um sistema simbólico de dominação, gera a neutralização de desigualdades. Como aponta Bourdieu, o campo jurídico subtrai as palavras e as locuções vulgares ao seu sentido corrente, para transformá-las em um código erudito distante dos "simples profanos". ${ }^{8}$ Com base nisso, Bourdieu mostra que "a situação judicial funciona como 'lugar neutro'", na medida em que "opera uma verdadeira 'neutralização' das coisas em jogo por meio da 'des-realização' e da distanciação implicadas na transformação directa dos interessados em diálogo entre mediadores", os "agentes especializados", produzindo-se, assim, "mesmo sem querer nem saber, uma distância neutralizante". ${ }^{9}$

Bourdieu mostra, também, que o trabalho jurídico funciona como uma ordem de conservação e de manutenção da ordem simbólica, na medida em que opera pela força da codificação (que subtrai as normas à contingência de um caso particular) e pela lógica dos precedentes judiciais, que "continuamente liga o presente ao passado" e "dá a garantia

como um dado negativo na estatística estatal e, do ponto de vista midiático, gera pouco interesse. Essa realidade precisa ser investigada do ponto de vista de uma teoria crítica, de uma filosofia pública e de uma democracia mais inclusiva.

8 BOURDIEU, 1989, p. 226.

9 BOURDIEU, 1989, pp. 226/227. 
de que [...] as transformações e as adaptações inevitáveis serão pensadas e ditas na linguagem da conformidade com o passado". ${ }^{10}$ Além disso, mostra que, "numa sociedade diferenciada, o efeito da universalização é um dos mecanismos, e sem dúvida dos mais poderosos, por meio dos quais se exerce dominação simbólica ou, se se prefere, a imposição da legitimidade de uma ordem social" ${ }^{11}$

Desse modo, o conservadorismo do Direito e das instituições jurídicas e o poder simbólico ${ }^{12}$ que está por trás do discurso jurídico encobrem a realidade e dificultam o rompimento do status quo social, na medida em que primam pela manutenção da ordem, mas de uma ordem estratificada que atende aos interesses de determinados grupos sociais e de poder, gerando uma falsa noção de normalidade sobre o estabelecimento das classes sociais.

Essas categorias jurídicas encobrem a realidade social, geram a negação dos problemas reais das comunidades, dos excluídos, que não usufruem de direitos básicos. Essas negatividades não são vistas, não chamam a atenção da grande mídia. Essa realidade está encoberta, ou se quer encobri-la. Além disso, essa negação ocorre pelos próprios excluídos,

10 BOURDIEU, 1989, p. 245.

11 BOURDIEU, 1989, 246.

12 “O poder simbólico, poder subordinado, é uma forma transformada, quer dizer, irreconhecível, transfigurada e legitimada, das outras formas de poder: só se pode passar para além da alternativa dos modelos energéticos que descrevem as relações sociais como relações de força e dos modelos cibernéticos que fazem delas relações de comunicação, na condição de se descrerem as leis de transformação que regem a transmutação das diferentes espécies de capital em capital simbólico e, em especial, o trabalho de dissimulação e de transfiguração (numa palavra, eufemização) que garante uma verdadeira transubstanciação das relações de força fazendo ignorarreconhecer a violência que elas encerram objectivamente e transformando-as assim em poder simbólico, capaz de produzir efeitos reais sem dispêndio aparente de energia." (BOURDIEU, 1989, p. 15) 
a partir da sua dominação, por meio de um dispositivo de poder que Foucault identificou como sendo as "disciplinas", mecanismos que manipulam comportamentos das pessoas, tornando-os dóceis. Foucault mostra, também, como esses mecanismos de poder geram um domínio sobre os corpos, uma anatomia política. ${ }^{13}$

Nesse sentido, esse poder invisível é capaz de fazer reproduzir um sistema que continua gerando exclusões e que continua beneficiando um outro grupo de cidadãos.

\subsection{Democracia para quem? Entre a democracia e o estado de exceção permanente}

Grande parte dos juristas atuais, quando se deparam com a temática da crise política e tentam analisá-la sob a

13 "Esses métodos que permitem o controle minucioso das operações do corpo, que realizam a sujeição constante de suas forças e lhes impõem uma relação de docilidade-utilidade, são o que podemos chamar as 'disciplinas'. Muitos processos disciplinares existiam há muito tempo: nos conventos, nos exércitos, nas oficinas também. Mas as disciplinas se tornaram no decorrer dos séculos XVII e XVIII fórmulas gerais de dominação. [...] O corpo humano entra numa maquinaria de poder que o esquadrinha, o desarticula e o recompõe. Uma 'anatomia política', que é também igualmente uma 'mecânica do poder', está nascendo; ela define como se pode ter domínio sobre o corpo dos outros, não simplesmente para que façam o que se quer, mas para que operem como se quer, com as técnicas, segundo a rapidez e a eficácia que se determina. A disciplina fabrica assim corpos submissos e exercitados, corpos 'dóceis'. A disciplina aumenta as forças do corpo (em termos econômicos de utilidade) e diminui essas mesmas forças (em termos políticos de obediência). Em uma palavra: ela dissocia o poder do corpo; faz dele por um lado uma 'aptidão', uma 'capacidade' que ela procura aumentar; e inverte por outro lado a energia, a potência que poderia resultar disso, e faz dela uma relação de sujeição estrita. Se a exploração econômica separa a força e o produto do trabalho, digamos que a coerção disciplinar estabelece no corpo o elo coercitivo entre uma aptidão aumentada e uma dominação acentuada." (FOUCAULT, 1999, pp. 118/119) 
perspectiva democrática, coloca foco nas instituições e na sua inter-relação. Preconiza-se a ideia de que, ao fim e ao cabo, o parlamento é, de um modo geral, o lugar por excelência onde devem ser tomadas as decisões, em nome do povo, porque, a par das suas contingências, representa a população de forma mais plural. Esses discursos jurídicos são, em geral, céticos quanto à forma de decisão dos Poderes Constituídos, pois, de modo geral, concluem que existe um jogo de interesses políticos e eleitoreiros nessa inter-relação, cujo foco não é o real interesse da comunidade. Sob essa perspectiva, diversos pesquisadores de direito constitucional comparado, como Ran Hirschl, veem esses problemas do constitucionalismo contemporâneo como contingências da própria democracia. ${ }^{14}$

No entanto, enquanto essa forma de fazer política atende a alguns, gera, para outros, exclusão na fruição de direitos e, por consequência, sofrimento real aos excluídos. A falta de infraestrutura urbana, de políticas públicas adequadas, de educação, de segurança pelo policiamento permanente nas

14 A esse respeito, Ran Hirschl: "The causal mechanisms behind the trend toward constitutionalization and judicialization in divided polities have not been adequately delineated by the major theories of constitutional transformation. As I have shown in this article, the 'consociational', evolutionist, systemic need-based (or the 'ungovernability'), 'new institutionalist', and electoral markets models cannot explain, for example, the recent history of constitutional entrenchment of rights and judicial review in Israel, Canada, New Zealand, and South Africa (to mention only the four cases I have examined in this paper). My brief analysis of constitutional politics in the above polities reveals that the wave of constitutionalization in these countries can be more productively understood, on the basis of an interest-based hegemonic struggle approach, as a conscious strategy undertaken by threatened political and economic elites seeking to preserve their hegemony through the insulation of policymaking from the democratic menace of popular political pressures. Moreover, what I have called the 'hegemonic preservation' thesis serves as a reminder that seemingly humanitarian constitutional reforms often mask an essentially self-serving agenda. The constitutionalization of rights, in other words, is often not so much the cause or a reflection of a progressive revolution in a given polity, as it is a means by which preexisting and ongoing sociopolitical struggles in that polity are carried out." (HIRSCHL, 2000, pp. 138/139) 
periferias urbanas gera a situação fática de insegurança e de aumento da criminalidade nessas comunidades. Contudo, ao invés da intervenção positiva consistente no aumento de políticas públicas, o Estado reforça a intervenção policial violenta, tratando o povo dessa comunidade com mais austeridade. ${ }^{15}$

15 Esse policiamento mais violento, com revistas pessoais constantes, invasões de residência sob alegação de flagrante delito, violência na abordagem com agressões é justificada pelo Estado diante da necessidade de garantir segurança para essa própria comunidade, já que nela existe maior criminalidade. Em alguma ou em grande medida, essa situação também é reproduzida no âmbito do Poder Judiciário, com prisões provisórias excessivas ou com penas mais severas. Comumente, as decisões que decretam as prisões provisórias, que deveriam ser a exceção, são justificadas sob o argumento de que "a sociedade não aguenta mais essa criminalidade", sendo "necessário" colocar um fim a esse "estado de insegurança" em que vive a sociedade. Assim, ainda que não conscientemente, coloca-se a população da periferia com uma alteridade quase completa, a partir da visão de que "esse outro" é causador da criminalidade e, portanto, que a prisão é "necessária" para garantir a "segurança da sociedade". De um lado, é claro que não cabe ao Judiciário, ao menos não primariamente, implementar políticas públicas positivas como saúde, educação, segurança pública, saneamento básico etc. Mas, de outro lado, a exclusão da população de comunidades carentes - periferia - é reforçada e reproduzida pelo Poder Judiciário com ainda mais exclusão, a partir da maior severidade no encarceramento. O Poder Legislativo também reforça a reprodução desse sistema de exclusão. Ao invés de um discurso de inclusão do outro e de elaboração de políticas públicas efetivas para as periferias, o problema da criminalidade é desenvolvido discursivamente a partir das dicotomias amigo e inimigo, do eu (ou do nós) e do outro, de criminalidade e de segurança. O resultado desses discursos comumente não é a proposição de redução das desigualdades ou a elaboração de políticas públicas positivas, senão o aumento da criminalização e das penas. O resultado de tudo isso não é a redução da criminalidade. Pelo contrário, nos últimos dez anos, observa-se que ocorreu um aumento vertiginoso da criminalidade e que coloca o Brasil como sendo o país que possui a segunda maior população carcerária do mundo. 
Assim, enquanto para alguns há democracia, para outros existe estado de exceção permanente. No dizer de Giorgio Agamben, o estado de exceção tem como fundamento a necessidade, que "justifica" uma fratura ou rompimento com o próprio direito, em que um juízo de sobrevivência ou subsistência "legitima" a ação. ${ }^{16}$

Desse modo, o Estado justifica esse estado de exceção permanente pela necessidade de intervir, gerando, ainda que velada ou sub-repticiamente, uma suspensão de direitos constitucionais. Nessa forma de agir, há dois problemas básicos: em primeiro lugar, os índices elevados de criminalidade derivam da falta de políticas públicas adequadas, ou seja, são causados pela própria inefetividade estatal; em segundo lugar, ao invés de corrigir esse problema, com a adequação de políticas públicas positivas, o Estado age de forma repressora, com o aumento da violência legítima, diante de uma situação de "necessidade" que ele próprio causou. Vale dizer, a "necessidade" que é causa desse estado de exceção velado

16 "Uma opinião recorrente coloca como fundamento do estado de exceção o conceito de necessidade. Segundo o adágio latino muito repetido (uma história da função estratégica dos adagia na literatura jurídica ainda está por ser escrita), necessitas legem non habet, ou seja, a necessidade não tem lei, o que deve ser entendido em dois sentidos opostos: "a necessidade não reconhece nenhuma lei" e "a necessidade cria sua própria lei" (necessité fait loi). Em ambos os casos, a teoria do estado de exceção se resolve integralmente na do status necessitatis, de modo que o juízo sobre a subsistência deste esgota o problema da legitimidade daquele" (AGAMBEN, 2007, p. 40). E continua Agamben: "Longe de responder a uma lacuna normativa, o estado de exceção apresenta-se como a abertura de uma lacuna fictícia no ordenamento, com o objetivo de salvaguardar a existência da norma e sua aplicabilidade à situação normal. A lacuna não é interna à lei, mas diz respeito à sua relação com a realidade, à possibilidade mesma de sua aplicação. É como se o direito contivesse uma fratura essencial entre o estabelecimento da norma e sua aplicação e que, em caso extremo, só pudesse ser preenchida pelo estado de exceção, ou seja, criando-se uma área onde essa aplicação é suspensa, mas onde a lei, enquanto tal, permanece em vigor" (AGAMBEN, 2007, pp. 48/49). 
e sub-reptício atinge violentamente a população carente, mas essa necessidade é causada pelo próprio Estado, pela falta de políticas públicas positivas e efetivas.

Dessa forma, esse estado de exceção permanente se oculta sub-repticiamente, não porque as práticas violentas de fissura nos direitos constitucionais terminam, senão porque ocorre uma "normalização" dessas práticas. Isto é, essas práticas de violação de direitos fundamentais são repetidas diariamente e, com o passar do tempo, passam a não mais gerar a indignação ou o repúdio que deveriam causar na população. Assim, o estado de exceção permanente paradoxalmente desaparece como tal - por essa normalização na consciência da população -, mas continua presente e cada vez mais cruel, atormentando e gerando sofrimento real a essa parcela da população oprimida e excluída.

Nesse sentido, o estado de exceção permanente está oculto pela própria democracia. O estado de exceção pretende não ser visto, porque apresenta dados negativos, porque mostra uma realidade que não é a dos romances, porque desperta um olhar assustado da comunidade internacional, porque conhecer essa realidade gera sofrimento. A par disso, ocorre um processo de normalização ou naturalização dessas desigualdades, na medida em que passa a não despertar mais a atenção das grandes mídias e do governo, o que encobre a realidade, que evita o sofrimento de pensar que os excluídos, vítimas do sistema, estão alijados de condições mínimas de vida e que possuem um sofrimento real. Há a banalização do mal, para usar uma expressão de Hannah Arendt. ${ }^{17}$

Portanto, é preciso indagar incessantemente: Como sair desse círculo vicioso de exclusão e de punição da exclusão com maior exclusão? Como sair desse estado de exceção permanente em que vivem os excluídos?

17 ARENDT, 2014. 
Do ponto de vista da teoria crítica, devem-se repensar os princípios democráticos e as instituições por uma outra perspectiva, que seja capaz de ouvir e sentir o povo, as suas necessidades, de captar o sentido das reivindicações que vêm das ruas, dos protestos que marcam os movimentos sociais. Os problemas sociais devem ser respondidos com políticas públicas positivas, e não pela perspectiva repressora e punitiva de um estado policial, que há muito tempo já se revela ineficaz.

Como propõe Dussel, é preciso pensar com a mente dos excluídos e ver a questão com os olhos do povo oprimido. ${ }^{18}$ Nesse contexto, como pensar numa nova forma de fazer política, diferente do modo como se organizaram os partidos políticos, as instituições estatais e como age a classe política em geral? Certamente, não existe uma solução simples para essa questão, nem deve haver um debate simplificador. Mas essa questão também não pode ser encarada com um olhar cético ou derrotista. Ao revés, é preciso investigar uma nova aporia, que esteja fora e além do conservadorismo do direito e do ceticismo sobre a política, que conceba a democracia na sua radicalidade modificadora. Nesse sentido, é necessário um olhar contrafactual, que constitua um novo paradigma de democracia, mas que, além disso, seja pragmático, estratégico, adequado e que coloque foco na voz que vem das ruas, nas manifestações populares, nos movimentos sociais.

18 “Cambiemos la piel! Adoptemos ahora 'metódica-mente' la del indio, del africano esclavo, del mestizo humillado, del campesino empobrecido, del obrero explotado, del marginal apiñado por millones miserables de las ciudades latinoamericanas contemporáneas. Tomemos como propios los 'ojos' del pueblo oprimido, desde 'los de abajo' [...]" (DUSSEL, 1994, p. 85) 


\section{Por uma democracia discursiva e comuni- tária: a descolonização da filosofia política e a reconstrução da democracia a partir do empoderamento e dos saberes de cada co- munidade}

Como foi mostrado acima, o conservadorismo do direito e o ceticismo da política não têm, em geral, contribuído para o desenvolvimento de modelos alternativos para enfrentar os problemas democráticos de participação efetiva dos cidadãos e da comunidade nas decisões políticas. Pelo contrário, esses saberes "especializados" comumente reforçam a violência epistêmica ${ }^{19}$ que atinge os excluídos, na medida em que recrudescem a dicotomia civilização-barbárie, cidadãos-marginais, amigo-inimigo, provavelmente porque não conseguiram se desvencilhar completamente do modo de pensar eurocentrista no projeto universalizante de modernidade.

Nesse sentido, talvez a filosofia política de Dussel possa permitir uma nova forma de investigar o problema, por trazer uma nova visão do princípio democrático, um olhar descolonizador da democracia, por pensar a questão do ponto de vista mais adequado aos povos da América Latina.

19 “La construcción del imaginario de la 'civilización' exigía necesariamente la producción de su contraparte: el imaginario de la 'barbarie'. Se trata en ambos casos de algo más que representaciones mentales. Son imaginarios que poseen una materialidad concreta, en el sentido de que se hallan anclados en sistemas abstractos de carácter disciplinario como la escuela, la ley, el Estado, las cárceles, los hospitales y las ciencias sociales. Es precisamente este vínculo entre conocimiento y disciplina el que nos permite hablar, siguiendo a Gayatri Spivak, del proyecto de la modernidad como el ejercicio de una 'violencia epistémica'." (CASTRO-GÓMEZ, 2000, p. 91) 
A esse respeito, a filosofia política de Dussel é libertadora, como ele próprio afirma, porque rejeita a perspectiva eurocentrista de democracia e encontra um novo sentido para o princípio democrático, considerando a complexidade muito maior da sociedade e das instituições na América Latina. ${ }^{20}$

Nesse sentido, Dussel parte do pressuposto de que toda ordem política é imperfeita, diante da finitude ou limitação humana. Reconhecendo essas contingências, afirma que a ordem política gera efeitos negativos inevitáveis, que atingem determinada parcela da população, os excluídos, as vítimas políticas, sobretudo em razão da assimetria na participação, ou da própria exclusão nessa participação. Isso demonstra que a ineficácia da ordem política, num mundo contingencial, gera sofrimento real às vítimas. ${ }^{21}$ Contrapondo-se a isso, surgem os movimentos sociais de contestação e, para dar suporte a esses movimentos, desenvolvem-se teorias críticas. Dussel afirma que a sua obra se insere dentro desta perspectiva, como uma filosofia política crítica, que tem como foco os movimentos sociais e ponto de apoio às vítimas políticas. ${ }^{22}$ Observa-se, assim, como Dussel complexifica a

20 DUSSEL, 1996.

21 “Todo orden político, aún el mejor empíricamente hablando, no es perfecto. Hemos ya indicado que para la condición humana finita tal tipo de acabamiento es imposible. Esto permite deducir que no siendo perfecto son inevitables, y más cuando se tiene en cuenta la incertidumbre de toda decisión humana, efectos negativos. Los que sufren los efectos negativos son las víctimas. Víctimas políticas en nuestro caso. Víctimas, porque no pueden vivir en el grado relativo a la evolución histórica de la humanidad; víctimas que de alguna manera se encuentran en asimetría en la participación, o simplemente han sido excluidas de la misma. En fin, el orden político manifiesta por sus víctimas su ineficacia, por el simple hecho de haber dichas víctimas - en cuanto no puede distribuir a todos los beneficios del orden vigente." (DUSSEL, 2006, p. 61)

22 “De tal manera que en esta Segunda parte la filosofía política deviene crítica del sistema vigente; comienza así una deconstrucción de lo expuesto en la Primera parte. El punto de apoyo de la tarea deconstructiva serán las mismas 
filosofia política tendo por pressuposto um modo de pensar crítico da realidade.

Nesse sentido, Dussel é um dos grandes precursores da filosofia da libertação, que, na sua essência, é especulativa e teórica, mas que tem por objetivo descobrir e expor todos os momentos negados e toda a exterioridade sem justiça, ou seja, é uma filosofia que tem como base o pobre, o oprimido, o outro. Desse modo, constitui-se num modo de pensar a partir das reivindicações do povo, do pobre, do excluído, pretendendo ser a expressão máxima da consciência crítica possível nessa perspectiva. ${ }^{23}$

Além disso, uma das grandes inovações de Dussel é desenvolver uma nova concepção de democracia, que seja concreta, adequada e apropriada aos países da América Latina. ${ }^{24}$ Ele propõe uma democracia que, além de discursiva,

víctimas políticas, oprimidas, reprimidas, excluídas [...]" (DUSSEL, 2006, p. 61)

23 “La filosofía de la liberación es una operación pedagógica, desde una praxis que se establece en la proximidad maestro-discípulo, pensador-pueblo, intelectual orgánico, diría Gramsci, en el pueblo. Aunque pedagógica, es una praxis condicionada por la praxis política (y también erótica). Sin embargo, como pedagógica, su esencia es especulativa, teórica. La praxis teórica, o la acción poiético intelectual esclarecedora del filósofo, se encamina a descubrir y exponer (en la exposición y el riesgo de la vida del filósofo), ante el sistema, todos los momentos negados y toda la exterioridad sin justicia. Por ello es una pedagógica sin analéctica de la liberación. Es decir, es el magisterio que cumple en nombre del pobre, del oprimido, del otro, el que como rehén dentro del sistema testimonia el fetichismo de dicha totalidad y predice su muerte en el acto liberador del dominado. Pensar todo a la luz de la palabra interpelante del pueblo, del pobre, de la mujer castrada, del niño y la juventud culturalmente dominados, del anciano descartado por la sociedad de consumo, con responsabilidad infinita y ante el Infinito, eso es filosofía de la liberación. La filosofía de la liberación debería ser la expresión del máximo de conciencia crítica posible." (DUSSEL, 1996, pp. 206/207)

24 DUSSEL, 2006, pp. 56/57. 
seja comunitária. Nesse sentido, afirma que o povo não deve ser encarado apenas como um dado, como um sujeito histórico fetichizado, mas deve ser visto como um ator político coletivo, como crítico da realidade, com vontade de viver e que deve buscar uma ordem política mais igualitária. ${ }^{25}$

Assim, Dussel utiliza uma metodologia que não é apenas crítico-reflexiva, mas também é propositiva. Ele propõe a substituição do paradigma "Igualdad, Fraternidad, Libertad" por um novo postulado, que represente uma segunda emancipação dos povos da América Latina: "Alteridad, Solidariedad, Libertación". ${ }^{26}$

Desse modo, deve-se buscar um novo paradigma para a democracia, fora e além dos horizontes traçados pelo paradigma moderno eurocentrista. A democracia, além de discursiva, deve ser comunitária e emancipadora, ou seja, devolver o protagonismo político ao povo, a partir de mecanismos que garantam a cada comunidade desenvolver as suas potencialidades, a partir de suas especificidades, bem como garantir-lhe controle das instituições políticas, efetiva participação nos órgãos governamentais e instrumentos concretos e adequados para reivindicar as suas demandas e buscar soluções, dentro e fora do Estado, para atender às suas necessidades.

Além disso, também é preciso uma análise crítica sobre a violência epistêmica praticada pelos "especialistas", que é redutora de complexidade e excludente. Nesse sentido, é preciso dar ênfase aos saberes locais, que refletem a cultura, a memória e a história de determinada comunidade. Também é importante descortinar os saberes dominados, estes entendidos de acordo com a concepção foucaultiana, como “blocos de saber histórico que estavam presentes e masca-

25 DUSSEL, 2006, p. 61-67.

26 DUSSEL, 2006, p. 117. 
rados no interior dos conjuntos funcionais e sistemáticos e que a crítica pode fazer reaparecer, evidentemente através do instrumento da erudição", como "uma série de saberes que tinham sido desqualificados como não competentes ou insuficientemente elaborados", como "saberes ingênuos, hierarquicamente inferiores, saberes abaixo do nível requerido de conhecimento ou de cientificidade".${ }^{27}$ Desse modo, em alguma medida, é preciso promover a insurreição desses saberes locais e dominados contra os saberes especializados e o discurso científico concentradores de poder.

Desse modo, as propostas para a reconstrução de um novo paradigma democrático devem ter lastro numa filosofia libertadora, pensada a partir dos excluídos, e também colocar foco nos saberes locais e nos saberes dominados, devolvendo ao povo a centralidade do poder político.

\section{Alternativas para a construção de uma nova filosofia política, um novo paradigma de de- mocracia discursiva e comunitária e de um novo modo de fazer política: em busca do fundamento perdido}

Partindo da perspectiva crítica em relação à concepção histórica e filosófica eurocêntrica, Dussel mostra que a modernidade tem um conceito emancipador racional da humanidade, mas, ao mesmo tempo, pragmaticamente, desenvolve um mito irracional de justificação da violência, que imola homens e mulheres do mundo periférico, cuja vitimização é encoberta pelo argumento do sacrifício da modernização. ${ }^{28}$

27 FOUCAULT, 1998, p. 170.

28 “Se trata de ir hacia el origen del ‘Mito de la Modernidad'. La Modernidad tiene 
Embora, em teoria, as democracias ditas "modernas" tenham colocado o ser humano no centro do poder estatal, como sujeito do poder político ${ }^{29}$, pragmaticamente tal poder está centralizado numa elite política que, ainda que por meio de um discurso de legitimação, orienta a ordem jurídica, econômica, política e social para atender a determinados interesses, com base em sistemas simbólicos de dominação. Esses sistemas simbólicos, em alguma medida, possuem uma abertura para as reivindicações sociais, mas, em geral, as absorvem apenas para formar um discurso legitimador e não para realmente atender às necessidades sociais ou suprir as negatividades expostas nas reivindicações sociais.

Então, como pensar em novos mecanismos e instituições que efetivem uma democracia discursiva, comunitária e emancipadora? Como estabelecer mecanismos de internalização e absorção dos influxos das reivindicações populares?

un 'concepto' emancipador racional que afirmaremos, que subsumiremos. Pero, al mismo tiempo, desarrolla un 'mito' irracional, de justificación de la violencia, que deberemos negar, superar" (DUSSEL, 1994, p. 7). E continua Dussel: "La Modernidad, en su núcleo racional, es emancipación de la humanidade del estado de imadurez cultural, civilizatoria. Pero como mito, en el horizonte mundial, inmola a los hombres y mujeres del mundo periférico, colonial (que los amerindios fueron los primeros en sufrir), como víctimas explotadas, cuya victimación es encubierta con el argumento del sacrificio o costo de la modernización. Este mito irracional es el horizonte que debe trascender el acto de liberación (racional, como deconstructivo del mito; práctico-político, como acción que supera el capitalismo y la modernidad en un tipo transmoderno de civilización ecológica, de democracia popular y de justicia económica)" (DUSSEL, 1994, p. 147).

29 "Tudo ocorre como se, no mesmo passo do processo disciplinar através do qual o poder estatal faz do homem enquanto vivente o próprio objeto específico, entrasse em movimento um outro processo, que coincide grosso modo com o nascimento da democracia moderna, no qual o homem como vivente se apresenta não mais como objeto, mas como sujeito do poder político." (AGAMBEN, 2002, p. 17) 
Como pensar numa democracia que estabeleça e internalize o discurso intersubjetivo da razão do outro? Como pensar em novos mecanismos de fazer política, mais democráticos e menos fetichizadores do poder?

\subsection{A abertura de um espaço de descontinuidade a partir do retorno à vida nua}

Para buscar alternativas ao atual modelo institucional brasileiro e ao modo com que as autoridades eleitas fazem política, bem como para buscar respostas para as problematizações feitas acima, é preciso adotar uma metodologia de rompimento com os paradigmas postos, em busca de uma nova aporia, a partir de uma radicalidade transformadora, mas sem deixar, ao final, de confrontar as hipóteses de pesquisa com o plano do mundo vivencial.

Como sugere Agamben, talvez seja necessário pensar o direito na sua não-relação com a vida, e a vida em sua não-relação com o direito, abrindo um novo caminho de reflexão para tomar a ação humana como política ${ }^{30}$ na sua pureza. Enfim, talvez seja preciso repensar a filosofia política num espaço de descontinuidade, na sua não-relação com o direito e com as instituições políticas pré-concebidas, para buscar alternativas às pré-compreensões e aos modelos institucionais já existentes. E, somente quando houver reais alternativas, a partir de novas utopias, confrontá-las na sua possibilidade de aplicação prática no mundo da vida.

Nessa perspectiva, uma via alternativa é o abandono da problematização da questão à luz dos modelos jurídico-

30 "Mostrar o direito em sua não-relação com a vida e a vida em sua não-relação com o direito significa abrir entre eles um espaço para a ação humana que, há algum tempo, reivindicava para si o nome 'política'." (AGAMBEN, 2007, p. 133) 
-institucionais tradicionais, que partem de pré-compreensões de instituições jurídicas pensadas para uma outra sociedade, para um outro tempo histórico, para uma outra cultura, para uma outra forma de pensar e para um outro continente. Propõe-se, ao revés, uma forma de pensar as instituições políticas a partir de uma teoria crítica, uma nova utopia, que gere empoderamento do povo a partir de baixo, como formas reais de participação do povo e veiculação de suas demandas sociais ao Estado, e não uma forma pseudo legitimadora, em que pessoas do ambiente político, ligadas a esse ou àquele político ou partido, nada acrescentam em termos de heterogeneidade ou legitimação, mas, pelo contrário, sob a máscara da legitimidade, representam apenas a perpetuação das elites políticas no poder.

Do ponto de vista da Teoria Crítica, Dussel propõe uma filosofia da libertação, que afirma a razão como capaz de estabelecer um diálogo, um discurso intersubjetivo com a razão do outro, como razão alternativa. ${ }^{31}$

Contudo, não se propõe apenas incluir os excluídos no atual sistema político, até mesmo porque essas tentativas não têm, na prática, efetivamente acrescentado poder ao povo. Muito além disso, os excluídos devem ser incluídos como iguais em novo momento institucional, num modelo institucional que tenha um grau superior de legitimidade e de participação, como aponta Dussel. ${ }^{32}$

31 Tradução livre do seguinte texto: “La Filosofía de la Liberación afirma la razón como facultad capaz de establecer un diálogo, un discurso intersubjetivo con la razón del otro, como razón alternativa." (DUSSEL, 1994, p. 168). E continua Dussel: “En nuestro tiempo, como razón que niega el momento irracional del 'Mito sacrificial de la Modernidad', para afirmar (subsumido en un proyecto liberador) el momento emancipador racional de la Ilustración y la Modernidad, como Trans-modernidad." (DUSSEL, 1994, p. 168)

32 Los excluidos no deben ser incluidos (sería como introducir al Otro en lo 
Nesse sentido, tendo como suporte os movimentos sociais e as manifestações populares, a filosofia política e a teoria crítica devem buscar a problematização dos dogmas já postos, das instituições políticas como funcionam na prática, mas não para descambar para um niilismo ou para um anarquismo, senão para realocar o povo, pragmaticamente, para a centralidade da vida política do Estado, vale dizer, como efetivo sujeito, e não como objeto do poder político.

Com isso, não se quer dizer que os excluídos devem tomar à força o Poder Estatal, até mesmo porque a tomada do poder geraria novos excluídos. A esse respeito, John Holloway - diversamente de Dussel - propõe, a partir do mau exemplo dado pela União Soviética, que o caminho da revolução não deve ser a conquista do poder, senão a dissolução das relações de poder, para criar uma sociedade de reconhecimento mútuo da dignidade das pessoas. ${ }^{33}$

Não se pretende propor que o modelo jurídico-institucional seja abandonado, tampouco separado do estudo

Mismo) en el antiguo sistema, sino que deben participar como iguales en un nuevo momento institucional (el nuevo orden político)." (DUSSEL, 2006, p. 75)

33 "The only way in which the idea of revolution can be maintained is by raising the skates. The problem of the traditional concept of revolution is perhaps not that it aimed too high, but that it aimed too low. The notion of capturing positions power, whether it be governmental power or more dispensed positions of power, to create a society based on the mutual recognition of people's dignity. What has failed is the notion that revolution means capturing power in order to abolish power. What is now on the agenda is the much more demanding notion of a direct attack on power relations. The only way in which revolution can now be imagined is not as the conquest of power but as the dissolution of power. The fall of the Soviet Union not only meant disillusionment for millions; it also brought the liberation of revolutionary thought, the liberation from the identification of revolution with the conquest of power. This, then, is the revolutionary challenge at the beginning of the twenty-first century: to change the world without taking power." (HOLLOWAY, 2013, p. 9) 
do modelo biopolítico de poder - até mesmo porque essas duas análises não podem ser completamente separadas, como ensina Agamben $^{34}$-, senão apenas que a busca de alternativas viáveis para a maior absorção das reivindicações populares está mais ligada ao modelo biopolítico de poder, ou seja, a uma investigação centrada no poder político que emana da vida nua.

\subsection{Alternativas factuais e contrafactuais de to- mada do poder pelo povo, dentro e fora das instituições estatais: por uma participação popular e comunitária efetiva}

A partir da perspectiva crítica desenvolvida anteriormente, devem ser pensadas alternativas viáveis para os problemas políticos e institucionais antes expostos, que sejam tendentes a gerar a efetiva inclusão e empoderamento do povo no exercício da vida política, dentro e fora do Estado.

Assim, a busca pela legitimidade que vem de baixo talvez não esteja somente no horizonte da estatalidade, ou

34 "A presente pesquisa concerne precisamente este oculto ponto de intersecção entre o modelo jurídico-institucional e o modelo biopolítico do poder. O que ela teve de registrar entre os seus prováveis resultados é precisamente que as duas análises não podem ser separadas e que a implicação da vida nua na esfera política constitui o núcleo originário - ainda que encoberto - do poder soberano. Pode-se dizer, aliás, que a produção de um corpo biopolítico seja a contribuição original do poder soberano. A biopolítica é, nesse sentido, pelo menos tão antiga quanta a exceção soberana. Colocando a vida biológica no centro de seus cálculos, o Estado moderno não faz mais, portanto, do que reconduzir à luz o vínculo secreto que une a o poder à vida nua, reatando assim (segundo uma tenaz correspondência entre moderno e arcaico que nos é dado verificar nos âmbitos mais diversos) com o mais imemorial dos arcana imperii." (AGAMBEN, 2002, p. 14) 
seja, na participação de cidadãos em órgãos de governo, senão na criação de mecanismos de mobilização e reivindicação nas próprias comunidades, que levem os problemas, as soluções e as reivindicações, com instrumentos de pressão, aos órgãos governamentais. Além da participação heterogênea dos cidadãos nos órgãos e conselhos estatais, talvez seja tão importante quanto isso os mecanismos de mudar o mundo sem tomar o poder, usando-se uma perspectiva de John Holloway. ${ }^{35}$

Nesse sentido, devem ser fomentadas iniciativas de organização e reivindicação social como o orçamento participativo, a formação de cooperativas, de associações para diversas finalidades sociais, organizações da sociedade civil etc. Tais iniciativas, ainda que com as suas contingências e imperfeições, são capazes de permitir que as próprias comunidades conheçam os seus problemas e possam, de forma organizada, a partir da formação de uma pauta de reivindicações, pressionar os órgãos governamentais para o atendimento dessas necessidades sociais, ou elas próprias, a partir das suas próprias forças, atuarem fora do poder estatal para atender às necessidades dos menos favorecidos, melhorar as condições da comunidade, mudar a cultura constitucional etc. É claro que tais iniciativas já existem, mas, no projeto institucional comunitário que se propõe, elas devem ocupar o centro do poder político, juntamente com os poderes estatais, mas fora do governo.

Além disso, numa perspectiva de democracia discursiva, comunitária e emancipadora, os movimentos sociais devem ser fomentados, na medida em que, através deles, ganham voz as mulheres, os homossexuais, os negros, os portadores de necessidades especiais, os sem-terra, os sem-teto, etc., que, em conjunto e de forma organizada, conseguem

35 HOLLOWAY, 2013. 
ter mais força para pressionar e pautar os seus interesses na agenda dos Poderes Estatais. Nessa perspectiva de democracia, os excluídos formam um outro poder, o Poder Popular, com representantes eleitos pelos próprios movimentos sociais, com atribuições de pautar as reinvindicações sociais e controlar os órgãos governamentais.

Do ponto de vista institucional, é preciso ir muito além do modelo liberal da tripartição de poderes, até mesmo porque a política tem mostrado que, na prática, esse sistema reforça o poder das elites políticas e que, em geral, não existe verdadeiro embate entre eles, ou seja, não existem tantos freios e contrapesos.

A esse respeito, já no plano institucional, devem ser criados mecanismos para uma democracia efetivamente comunitária, com o estabelecimento de líderes comunitários de bairros, que tenham poder político de apresentar os problemas dessa comunidade e empregar os recursos orçamentários nas questões que mais a afetam. Com efeito, o estabelecimento de líderes comunitários e a sua eleição fomentam o conhecimento dos problemas locais pela própria comunidade, além do fato de que eles estariam mais próximos dos problemas locais e dos influxos das pressões da comunidade por melhores condições de vida para todos. ${ }^{36}$

36 Algo semelhante ocorre com o empoderamento dos povos e nações indígenas campesinos a Constituição da Bolívia, que dá ênfase a essa perspectiva comunitária de democracia, no seu artigo 11: “Artículo 11. I. El Estado adopta para su gobierno la forma democrática participativa, representativa y comunitaria, con equivalencia de condiciones entre hombres y mujeres. II. La democracia se ejerce de las siguientes formas, que serán desarrolladas por la ley: 1. Directa y participativa, por medio del referendo, la iniciativa legislativa ciudadana, la revocatoria de mandato, la asamblea, el cabildo y la consulta previa, entre otros. Las asambleas y cabildos tendrán carácter deliberativo. 2. Representativa, por medio de la elección de representantes por voto universal, directo y secreto, entre otros. 3. Comunitaria, por medio de la elección, designación o nominación de autoridades por normas y procedimientos propios de los pueblos y naciones indígena originario campesinos, entre otros." (BOLÍVIA, 2018) 
Outra medida importante talvez seja o estabelecimento de mecanismos comunitários de julgamento de conflitos, mediante a eleição de juízes leigos ou juízes de paz (ou outro nome que se possa dar) pela própria comunidade, com competência para julgar conflitos internos dessa comunidade - sobretudo relativos a direito de vizinhança - com base na equidade, à semelhança do permissivo da Constituição do Equador. ${ }^{37}$

Além disso, é importante criar mecanismos para que esses movimentos sociais sejam representados em órgãos estatais, bem como tenham efetivo controle das políticas públicas desenvolvidas. Uma medida possível, seria, por exemplo, a criação de conselhos estatais com poder político, compostos por representantes eleitos desses movimentos sociais.

Outra questão que precisa ser discutida é a possibilidade de impeachment do Presidente da República, de governadores de Estados e do Distrito Federal, de prefeitos, e

37 O art. 189 da Constituição do Equador de 2008 assim estabelece: "Art. 189. Las juezas y jueces de paz resolverán en equidad y tendrán competencia exclusiva y obligatoria para conocer aquellos conflictos individuales, comunitarios, vecinales y contravenciones, que sean sometidos a su jurisdicción, de conformidad con la ley. En ningún caso podrá disponer la privación de la libertad ni prevalecerá sobre la justicia indígena. Las juezas y jueces de paz utilizaran mecanismos de conciliación, dialogo, acuerdo amistoso y otros practicados por la comunidad para adoptar sus resoluciones, que garantizarán y respetarán los derechos reconocidos por la Constitución. No será necesario el patrocinio de abogada o abogado. Las juezas y jueces de paz deberán tener su domicilio permanente en el lugar donde ejerzan su competencia y contar con el respeto, consideración y apoyo de la comunidad. Serán elegidos por su comunidad, mediante un proceso cuya responsabilidad corresponde al Consejo de la Judicatura y permanecerán en funciones hasta que la propia comunidad decida su remoción, de acuerdo con la ley. Para ser jueza o juez de paz no se requerirá ser profesional en Derecho." (EQUADOR, 2018) 
de outras autoridades eleitas, pelo plebiscito, seja em razão de crimes de responsabilidade ou por descumprimento da proposta ou plano de trabalho apresentados nas eleições e registrados no cartório eleitoral. Na Constituição da Bolívia de 2007, por exemplo, existe o instituto da revocatória de mandato, que consiste, em síntese, na possibilidade de convocar um referendo popular para cassar o mandato de uma autoridade que exerça cargo eletivo, mediante o voto de maioria simples dos cidadãos ${ }^{38}$. De modo semelhante, a Constituição do Equador de 2008 permite convocar um referendo popular para cassar o mandato de autoridades eleitas pelo povo. ${ }^{39}$ A Constituição da Colômbia de $1991^{40}$

38 Constituição da Bolívia de 2007: “Artículo 187. I. Toda persona que ejerza un cargo electo podrá ser revocada de su mandato. II. La revocatoria del mandato podrá solicitarse cuando haya transcurrido al menos la mitad del periodo del mandato. La revocatoria del mandato no podrá tener lugar durante el último año de la gestión en el cargo. III. El referendo revocatorio procederá por iniciativa ciudadana, a solicitud de al menos el veinte por ciento de votantes del padrón electoral de la circunscripción que eligió a la servidora o al servidor público. IV. La revocatoria del mandato de la servidora o del servidor público procederá si en el resultado del referendo revocatorio el número de votos a favor de la revocatoria es superior al número de votos en contra. V. La revocatoria sólo procederá una sola vez en cada mandato constitucional del cargo electo." (BOLÍVIA, 2018)

39 Constituição do Equador de 2008: “Art. 105. Las personas en goce de los derechos políticos podrán revocar el mandato a las autoridades de elección popular. La solicitud de revocatoria del mandato podrá presentarse una vez cumplido el primero y antes del último año del periodo para el que fue electa la autoridad cuestionada. Durante el periodo de gestión de una autoridad podrá realizarse sólo un proceso de revocatoria del mandato. La solicitud de revocatoria deberá respaldarse por un número no inferior al diez por ciento de personas inscritas en el registro electoral correspondiente. Para el caso de la Presidenta o Presidente de la República se requerirá el respaldo de un número no inferior al quince por ciento de inscritos en el registro electoral." (EQUADOR, 2018)

40 Constituição Política da Colômbia, de 1991: “Artículo 40. Todo ciudadano 
e a Constituição Venezuelana de $1999^{41}$ também permitem a revocatória de mandato pelo voto popular, que pode ser aplicada para todos cargos eletivos, ainda que aquela não estabeleça em seu texto o procedimento da revocatória.

Se fosse adotado no Brasil um sistema semelhante à revocatória de mandato, o governante ou parlamentar ficaria sujeito ao processo de impeachment caso tivesse cometido algum ato de corrupção ou descumprido as suas promessas de campanha (plano de trabalho) e perdido o apoio popular. Além disso, a sua prestação de contas ao povo seria uma constante. Com a necessidade de apoio popular para se manter no poder, as medidas políticas estariam sempre sujeitas a um diálogo franco e sincero com o povo.

Além disso, essas propostas concretas devem ser compreendidas dentro do experimentalismo institucional, de modo que se possa aprender com os próprios erros e se autocorrigir, a partir da vivência institucional no contexto do processo performativo de uma democracia.

Enfim, não se está aqui pretendendo esgotar as medidas para a concretização da democracia, na concepção que se propõe, tampouco apontar soluções simplistas para solucionar problemas carregados de complexidade, senão

tiene derecho a participar en la conformación, ejercicio y control del poder político. Para hacer efectivo este derecho puede: [...] 4. Revocar el mandato de los elegidos en los casos y en la forma que establecen la Constitución y la ley." (COLÔMBIA, 2018)

41 Constituição da Venezuela de 1999: “Artículo 72. Todos los cargos y magistraturas de elección popular son revocables. Transcurrida la mitad del período para el cual fue elegido el funcionario o funcionaria, um número no menor del veinte por ciento de los electores o electoras inscritos en la correspondiente circunscripción podrá solicitar la convocatoria de un referendo para revocar su mandato. [...] Durante el período para el cual fue elegido el funcionario o funcionaria no podrá hacerse más de una solicitud de revocación de su mandato." (VENEZUELA, 2018) 
buscar uma nova aporia para além do sistema tradicional de tripartição de poderes, bem como indicar exemplificativamente mecanismos alternativos para a implementação de uma democracia discursiva, comunitária e emancipadora, a partir de experiências latino-americanas, que devem ser discutidas à luz da realidade brasileira e que realoquem o povo na centralidade do poder político, dentro e fora do Estado.

\section{Considerações finais}

As manifestações populares que ocorrem desde 2013 dão o tom do descontentamento popular com a classe política, com os representantes eleitos e com o atual modelo de fazer política. Tendo como pano de fundo as manifestações populares e os movimentos sociais, é preciso, a partir da teoria crítica e da filosofia política, desconstruir alguns pilares sobre os quais tem se fundado as perspectivas conservadoras do direito e ceticistas da política, para mostrar o que está encoberto.

Nesse sentido, o Direito opera como um sistema simbólico de dominação, em conjunto com outros sistemas, gerando a neutralização e a naturalização de desigualdades, como mecanismo de conservação da ordem simbólica a partir da codificação, o que fomenta a reprodução de um sistema global que gera exclusões e que dificulta o rompimento com o status quo social.

As análises políticas, com a perspectiva cética acerca do jogo de interesses que permeia a relação entre os membros dos Poderes Constituídos, também não ajudam a abrir novos horizontes para a construção de um novo modelo democrático e institucional. Pelo contrário, juntamente com o Direito, ajuda a encobrir a violência epistêmica que atinge os excluídos. 
Além disso, a forma atual de fazer política atende a interesses de alguns grupos hegemônicos, enquanto gera sofrimento real para as vítimas políticas, os excluídos, que são marginalizados pela falta de políticas públicas positivas e pelas políticas criminais repressoras. Assim, enquanto alguns desfrutam de uma democracia, outros vivem num estado de exceção permanente, ocultado pela própria democracia. A reprodução desse sistema global gera a "naturalização" dessas desigualdades e o encobrimento das vítimas políticas, o que deve ser objeto de uma teoria crítica, que veja o mundo pela perspectiva dos excluídos, que seja contrafactual, mas que, ao mesmo tempo, seja adequada, estratégica e apropriada para colocar no centro das discussões as reivindicações dos movimentos sociais e das manifestações populares.

Desse modo, devem se buscar respostas a esses problemas a partir de perspectivas descolonizadoras da filosofia política, da sua reorientação, da construção de modelos instituidores de um novo paradigma de democracia, que seja discursiva, comunitária e emancipadora. Nesse ínterim, a filosofia política libertadora de Dussel ajuda a encontrar uma nova forma de pensar o problema, porque coloca como pano de fundo as vítimas políticas e traz um olhar descolonizador da democracia.

Assim, é possível abrir caminho para uma nova concepção de democracia, mais procedimentalista, comunitária e emancipadora, a partir das construções teóricas e das experiências concretas dos povos da América Latina, considerando a sua complexidade e as suas especificidades. Desse modo, é possível conceber a democracia para além da justificação das suas instituições, mas na sua radicalidade modificadora. Assim, a reconstrução de um novo paradigma democrático deve ter lastro numa filosofia libertadora, pensada a partir dos excluídos, e também colocar foco nos saberes locais e 
nos saberes dominados, devolvendo ao povo a centralidade do poder político.

Para tanto, é preciso repensar a filosofia política a partir do rompimento com os paradigmas postos, dentro de um espaço de descontinuidade, de uma radicalidade transformadora, na sua não-relação com o direito e com as instituições políticas pré-concebidas, para buscar novas utopias, que sejam alternativas às pré-compreensões e aos modelos institucionais já existentes, para, somente após, confrontá-las com a possibilidade de sua aplicação prática no mundo da vida.

Nesse sentido, é preciso pensar em alternativas factuais e contrafactuais de empoderamento do povo no exercício da vida política, dentro e fora do Estado, na trilha da participação popular e comunitária efetiva, tendentes a gerar a efetiva inclusão dos excluídos num novo modelo democrático.

Desse modo, as alternativas concretas devem ser buscadas com base nesse novo paradigma democrático e na complexidade da diversidade social, para além do sistema tradicional de tripartição de poderes, que gere efetivo empoderamento do povo e da comunidade, levando em consideração as experiências constitucionais e concretas latino-americanas, que devem ser discutidas e internalizadas à luz da realidade brasileira, mas que sejam capazes de devolver ao povo (plebs) - a partir de uma perspectiva crítica e de descontinuidade - a centralidade do poder político.

\section{Referências}

AGAMBEN, Giorgio. Estado de exceção. (Trad. Iraci D. Poleti). 2. ed. São Paulo: Boitempo, 2007.

. Homo Sacer: O Poder Soberano e a Vida Nua I (Trad. Henrique Burigo). 2. ed. Belo Horizonte: UFMG, 2002. 
ARENDT, Hannah. Eichmann em Jerusalém: um relato sobre a banalidade do mal. (Trad. José Rubens Siqueira). 17. reimpr. São Paulo: Companhia das Letras, 2014.

BOLÍVIA. Constitución Politica del Estado Plurinacional de Bolívia. Gaceta Oficial, La Paz, 24 nov. 2007. Disponível em: <https://www.transparencialegislativa.org/wp-content/ uploads/2013/04/Constitucio\% CC\%81n-Bolivia.pdf>. Acesso em: 7 nov. 2018.

BOURDIEU, Pierre. A Força do Direito: elementos para uma sociologia do campo jurídico. In: O poder simbólico (Trad. Fernando Tomaz). Rio de Janeiro: Bertrand, 1989. cap. 8, pp. 209-254.

. Sobre o Poder Simbólico. In: . O poder simbólico (Trad. Fernando Tomaz). Rio de Janeiro: Bertrand, 1989. cap. 1, pp. 7-16.

CASTRO-GÓMEZ, Santiago. Ciencias sociales, violencia epistémica y el problema de la "invención del otro". In: LANDER, Edgardo (Org.). La colonialidad del saber: eurocentrismo y ciencias sociales. Perspectivas latino-americanas. Buenos Aires: CLACSO, 2000. pp. 88-98

COLÔMBIA. Constitución Política de Colombia, de 6 de julho de 1991. Gaceta Constitucional, Bogotá, 7 de jul. 1991. Disponível em: <https://www.procuraduria.gov. co/guiamp/media/file/Macroproceso\%20Disciplinario/ Constitucion_Politica_de_Colombia.htm>. Acesso em: 7 nov. 2018.

DUSSEL, Enrique. 1492: el encubrimiento del otro: hacia el origen del mito de la modernidad. Plural Editores: La Paz, 1994.

20 Tesis de Política. 2. ed. México: Siglo XXI, 2006. . Filosofía de la liberación. 4. ed. Nueva América: Bogotá, 1996. 
EQUADOR. Constitución de la República del Ecuador, de 25 de julho de 2008. Registro Oficial, Quito, 20 out. 2008. Disponível em: <http://www.asambleanacional.gov.ec/ documentos/constitucion_de_bolsillo.pdf>. Acesso em: 7 nov. 2018.

ÉPOCA. 12 de abril: os protestos pelo Brasil. Disponível em: <http:/ / epoca.globo.com/tempo/noticia/2015/04/12-de-abril-os-protestos-pelo-brasil.html>. Acesso em: 6 nov. 2018.

FOLHA DE SÃO PAULO. Protestos contra o governo reúnem quase 1 milhão pelo país. Disponível em: <http:/ / www1.folha.uol.com.br/poder/2015/03/1603286-protestos-contra-o-governo-reune-quase-1-milhao-pelo-pais. shtml>. Acesso em: 6 nov. 2018.

FOUCAULT, Michel. Microfísica do poder (Trad. Roberto Machado). 13. ed. Rio de Janeiro: Graal, 1998.

. Vigiar e punir: nascimento da prisão (Trad. Raquel Ramalhete). 20. ed. Petrópolis, RJ: Vozes, 1999.

G1. Mapa das manifestações no Brasil, domingo, 15/03. Disponível em: <http:/ / especiais.g1.globo.com/politica/ mapa-manifestacoes-no-brasil/15-03-2015/>. Acesso em: 6 nov. 2018-a.

G1. Mapa das manifestações no Brasil, domingo, 12/04. Disponível em: <http:/ / especiais.g1.globo.com/politica/ mapa-manifestacoes-no-brasil/12-04-2015/>. Acesso em: 6 nov. 2018-b.

G1. Mapa das manifestações no Brasil. Disponível em: <http:/ / especiais.g1.globo.com/politica/mapa-manifestacoes-no-brasil/todos/>. Acesso em: 6 nov. 2018-c.

HIRSCHL, Ran. The Political Origins of Judicial Empowerment through Constitutionalization: Lessons from Four 
Constitutional Revolutions. Law \& Social Inquiry, Chicago, v. 25, n. 1, pp. 91-149, jan. 2000.

HOLLOWAY, John. Change the World without taking power: the meaning of revolution today. London: Pluto Press, 2013. IBOPE. 89\% dos manifestantes não se sentem representados por partidos. Disponível em: <http://www.ibope.com. br/pt-br/noticias/Paginas/89-dos-manifestantes-nao-se-sentem-representados-por-partidos.aspx>. Acesso em: 6 nov. 2018-a.

. Pesquisa de opinião pública sobre as manifestações. Disponível em: <http://www.ibope.com.br/pt-br/noticias/Documents/JOB_0948_BRASIL\%20-\%20Relatorio\%20 de\%20tabelas.pdf>. Acesso em: 6 nov. 2018-b.

VENEZUELA. Constitución de la República Bolivariana de Venezuela, de 15 de dezembro de 1999. Gaceta Oficial del jueves, Caracas, 30 dez. 1999. Disponível em: <http:/ / www. cne.gob.ve/web/normativa_electoral/constitucion/indice. php>. Acesso em: 12 nov. 2018.

Recebido em 19/11/2018

Aprovado em 12/04/2019

Fabrício Castagna Lunardi

E-mail: fabricioclunardi@yahoo.com.br 
